\title{
Maculopapular Lesion
}

National Cancer Institute

\section{Source}

National Cancer Institute. Maculopapular Lesion. NCI Thesaurus. Code C75579.

A skin condition consisting of both macules and papules. 